\title{
LOS VERDADEROS “TRAIDORES” EN EL PENSAMIENTO DE ADOLFO GILLY. UN COMENTARIO EN TORNO A SUS IDEAS SOBRE LA DECENA TRÁGICA
} Servando Ortoll*

RESUMEN: Un comentario en torno a las ideas que el historiador Adolfo Gilly sostiene en su obra, a propósito del asesinato de Francisco I. Madero; el autor sostiene una tesis diferente, según la cual hay que revalorar varias figuras -Huerta, Félix Díaz, el mismo Madero, Lascuráin, León de la Barra, Cólogan-, para interpretar correctamente -fuera de la historiografía oficial- los sucesos de la Decena Trágica.

Palabras ClaVE: Decena trágica, Victoriano Huerta, Francisco Madero, Félix Díaz, Adolfo Gilly.

RECEPCIÓN: 12 de septiembre de 2013. ACEPTACIÓN: 12 de noviembre de 2013.
ABSTRACT: This article is a commentary regarding historian Adolfo Gilly's ideas in his work on the murder of Francisco I. Madero. The author proposes reconsidering the roles of Huerta, Félix Díaz, Madero himself, Lascuráin, León de la Barra, and Cólogan, in order to accurately interpret the events of Ten Tragic Days, aside from the official historical account.

KeYwords: Ten Tragic Days, Victoriano Huerta, Francisco Madero, Félix Díaz, Adolfo Gilly.

* Instituto de Investigaciones Culturales-Museo. Universidad Autónoma de Baja California, campus Mexicali. 


\section{LOS VERDADEROS “TRAIDORES” \\ EN EL PENSAMIENTO \\ DE ADOLFO GILLY. \\ UN COMENTARIO EN TORNO \\ A SUS IDEAS SOBRE \\ LA DECENA TRÁGICA}

\begin{abstract}
A
primera vista, Cada quien morirá por su lado: una historia militar de la Decena Trágica ${ }^{1}$ semeja un complejo reloj de péndulo completo con su frontón, cuadrante de fases lunares, aguja de horas, minutero, caja, pesas y, por supuesto, péndulo. Pero una segunda y más cuidadosa mirada muestra una imagen totalmente distinta: el reloj de péndulo ha sido reconstruido con piezas de muchas otras maquinarias; su sonido es sordo, las pesas pertenecen a otra caja, el péndulo está abollado $y$, cuando se le activa manualmente, avanza con tropiezos. La diferencia entre lo que semeja ser esta nueva obra del profesor

${ }^{1}$ Adolfo Gilly, Cada quien morirá por su lado: una historia militar de la Decena Trágica, 2013, México, Ediciones Era, 198 pp.
\end{abstract}

Adolfo Gilly y lo que es, sorprenderá -y tal vez también desilusione- a todo lector cuidadoso. Los capítulos de este libro, al igual que el reloj de péndulo imaginario que he descrito, no siempre embonan y, aunque como libro este texto da la apariencia de erguirse solo, aparecen en él contradicciones (tanto de hecho como de interpretación) que debilitan irremediablemente el trabajo del autor, más interesado en aferrarse a la vieja historia oficial -o la que él mismo llamó en una ocasión "historiografía pragmáticamente impregnada de ideología estatal"- que en proponer nuevas e inéditas interpretaciones. ${ }^{2}$

\footnotetext{
2 "Prefacio a la edición en inglés", Adolfo Guilly, La revolución interrumpida, 1994, México, Ediciones Era, p. 11.
} 
Acabado de imprimir real o simbólicamente el 9 de febrero de 2013 -es decir, a cien años justos del golpe de Estado iniciado por los generales Félix Díaz y Manuel Mondragón en contra del gobierno de Francisco I. Madero-, el libro de Adolfo Gilly retoma viejas y maniqueas tesis carrancistas: Madero era bueno, pero incumplió sus promesas; era cándido e indeciso; estaba mal aconsejado y se dejaba llevar por la conmoción del momento, más que por el juicio sereno y premeditado; lo rodeaban hombres malos, con el traidor general Victoriano Huerta a la cabeza, quien era víctima de atávicos rencores indios (no son palabras de Gilly, pero se infieren a lo largo de su escrito). Sólo así se entiende que este último traicionara al hombre bueno, aunque un tanto despistado, que a los pocos meses de asumir la presidencia se había enemistado con sus más leales e incondicionales seguidores.

Extraña la postura actual de Gilly, porque en su afamada La revolución interrumpida, publicada por primera vez en 1971, se expresa así de Victoriano Huerta:

Victoriano Huerta no era el militar inepto y el borracho consuetudinario que presentan las historias oficiales, $[\mathrm{sic}]$ que han convertido a su figura en el villano de un cuento donde todos los demás jefes burgueses aparecen como héroes sin miedo y sin mancha. Si bien su afición a la bebida es un dato seguro, no era ése el rasgo que definía su carácter [...]. Era un militar que había mostrado condiciones en el campo de batalla y un político enérgico, capaz y despiadado, que debía ser tomado seriamente [sic] como en efecto lo hicieron sus enemigos de entonces. Esto lo demostró tanto al organizar la represión contrarrevolucionaria como al enfrentar las presiones del gobierno de [Woodrow] Wilson, que se fueron haciendo más fuertes y amenazantes en la medida en que Huerta buscaba apoyo en las potencias europeas, y en especial en Gran Bretaña. $^{3}$

La descripción de Huerta que hizo en 1971 se distancia de la que aparece en Cada quien morirá por su lado. Como decía arriba, contrasta el carácter del traidor general Victoriano Huerta, con el del bonachón de Madero, a quien lo acompañaba -al menos de palabra- el tranquilo y pausado general Felipe Ángeles. Fue a Ángeles a quien el presidente envió a la campaña en Morelos, para pacificar, de la manera más digna y prudente para ambos lados, a los zapatistas. Pero si Ángeles era cauto con el fusil, era ingenuo con la pluma, y Gilly retoma sus escritos precursores sobre el general (una de las varias piezas del reloj de péndulo que pro-

${ }^{3}$ Gilly, op. cit., p. 130. 
NOTAS

vienen de otro mecanismo) para remachar en la mente de sus lectores lo que ha repetido en incontables ocasiones: era obvio que el resentido y malintencionado de Huerta traicionara a Madero puesto que - ila evidencia lo demuestra!- habían entrado ambos en graves desacuerdos sobre política militar y Huerta no se lo perdonaría jamás. ${ }^{4}$

Gilly se equivoca. Victoriano Huerta tenía un gran sentido práctico de la vida y era de memoria corta. Diferencias e intercambios antiguos con Madero le resultaban indiferentes: a él le importaba el presente y resolver las condiciones según se presentaban. A su sentido práctico -y no a ese odio atávico que Gilly le atribuye- debe imputarse que se adhiriera a los sublevados, cuando vio lo fútil que sería continuar una lucha callejera en contra de la inexpugnable fortaleza (que no ratonera sin salida) en la que se habían alojado Félix y Mondragón, a poco de rebelarse contra del gobierno de Madero, el 9 de febrero de 1913.

Más allá de la visión simplista y predecible de Gilly, su libro adolece

${ }^{4}$ En La revolución interrumpida, Gilly se arriesga todavía más: "Cuando en ese mes [de febrero de 1913] Huerta, General en Jefe del Ejército de Operaciones, derribó al gobierno, hizo asesinar [sic] al presidente Francisco I. Madero y a su vicepresidente José María Pino Suárez, y ocupó la presidencia, era natural [sic] que contara con el apoyo y la aprobación del embajador norteamericano", op. cit., p. 120. de una gran debilidad, resultado de la tendencia, consciente o no del autor, por acallar a la oposición. Entristece que Gilly -ex militante de la IV Internacional y, como tal, conocedor en carne propia de lo significativo que es escuchar a las voces disidentesenmudezca la de Félix Díaz para repetir una vez más cuánto se debe mantener en alto la personalidad heroica de Felipe Ángeles, general pronunciadamente antifelicista y antihuertista. ${ }^{5}$ La historiografía "revolucionaria", es decir, carrancista, ha minimizado la figura de Félix Díaz. Cierto que se desempeñó en puestos que quizá no estuvieran a la altura de su alcurnia; pero nadie negará -al menos desde Fouchéque cualquiera con el puesto de jefe de la policía, en una ciudad como la de México, tiene acceso a información

${ }^{5}$ El 5 de marzo de 1915, Felipe Ángeles escribió: "Si he dicho que estoy dispuesto a estrechar contra mi pecho a todos los buenos mexicanos que no estén manchados por el crímen [sic], no puede ser más clara mi idea: para los que no tomaron participación en las atrocidades del felicismo y del huertismo no abrigo prevención alguna, aunque hayan sido mis enemigos y con tal [de] que se plieguen a las leyes emanadas de la Constitución política del país. A los responsables de los asesinatos y persecuciones que caracterizaron la tiranía de Huerta es indudable que no podré favorecerles [con] la impunidad, si bien desearía que se les juzgase con la Ley y ésta solamente fuera la que se les aplicara", Nueva York. New York Public Library (en adelante NYPL). Enrique Llorente Papers (ELLP). Carta del general Felipe Ángeles al licenciado Enrique C. Llorente. Monterrey, Nuevo León, 5 de marzo de 1915. 
que otros muchos desconocen. El apodado "sobrino de su tío" tenía razones para disentir: unas, por supuesto, personales; pero otras más basadas en lo que, él entendía, era el malestar que experimentaba el común de los mexicanos $-\mathrm{y}$ con esto me refiero a buena parte de la población de las ciudades, que no alcanzó ni la fama ni el renombre de rebeldes, como Pascual Orozco o Emiliano Zapata- bajo la férula de la familia Madero. ${ }^{6}$

${ }^{6}$ El miércoles 12 de febrero de 1913, en el transcurso de una conversación que el general Félix Díaz sostuvo en la Ciudadela con el embajador norteamericano y los ministros plenipotenciarios de España, Alemania e Inglaterra en torno al bombardeo de la ciudad, Díaz dijo: "que el derrocar este gobierno [de Madero] no era cuestión de ambición personal para él mismo, pero que [si se sublevó] fue con el deseo de expresar los sentimientos de toda la nación", Madrid. Ministerio de Asuntos Exteriores y de Cooperación (en adelante MAEC). Archivo General (AG). Signatura H 2558. "Memorandum of Conference Between the American Ambassador and the Ministers of Great Britain, Germany and [Spain] and General Felix Diaz, Held at the Ciudadela in the City of Mexico at 2:30 p.m., February 12, 1913". Desde el 15 de septiembre de 2012, este archivo fue "cerrado a la investigación". Doña Pilar Casado Liso, ex Jefa de Sala del Archivo General del Ministerio de Asuntos Exteriores y Cooperación, me explicó: "En un proceso de colaboración entre los ministerios de Asuntos Exteriores y de Cooperación y el de Educación, Cultura y Deportes, se está llevando a cabo el traslado de nuestros fondos históricos a archivos dependientes de la Secretaría de Estado de Cultura. El fondo histórico ya ha sido trasladado al Archivo Histórico Nacional, y el fondo renovado (desde 1930), está siendo trasladado, actualmente, al Archivo General de la Administración de Alcalá de Henares", Pilar Casado Liso, Jefa de Servicio de la Vicesecretaría General Técnica, Servicio de Archivo General, a Servando Ortoll. Madrid, 1 de julio de 2013. Para
Es una pena que, en vez de profundizar en la personalidad de Félix Díaz y sus razones para discrepar con el Madero que lo llevó a iniciar uno de los muchos levantamientos que se planeaban en contra del presidente, Gilly nos hable una vez más de Ángeles. Si insisto en escribir sobre las personalidades de Huerta y Ángeles es que, como lector e historiador, creo que las grandes plumas del gremio deberían esforzarse por salir del gabinete y escrutar personalmente los archivos, en vez de hacerlo por medio de experiencias vicarias; por buenos o sinceros que sean nuestros asistentes de investigación, nunca verán con nuestros ojos las huellas de temas verdaderamente innovadores y que pueden refrescar el escenario historiográfico de México.

En vez de esto, Cada quien morirá por su lado repite el camino andado y avanza y retrocede constantemente, pues el historiador Adolfo Gilly profesa una preferencia inexplicable-patente en el primero de sus capítulos y presente en los demás- por andar y recular: utiliza constantes y cansados flashbacks para, al parecer, explicar en mini-instantáneas por qué ciertos eventos desembocaron en lo que fueron. Más agradable y descansado hubiera sido para el lector-hablo en particular

las citas, utilizo la información que tomé del propio Archivo General del Ministerio de Asuntos Exteriores y Cooperación. 
de mi persona- encontrarse con una narrativa que fluyera, que contara todos los antecedentes importantes al inicio y que permitiera al lector entender enseguida los acontecimientos posteriores, según se fueron dando.

No olvido que ese primer capítulo, una vieja pieza de relojería supuestamente ajustada a la nueva maquinaria, no acaba por embonar con el resto de las piezas como debiera. Que no apaguen mis palabras la curiosidad del lector: conforme avanza en su relato, la obra se aligera; el autor abandona las trilladas tesis sobre la prensa opositora y cómo influyó en la caída de Madero, y se enfoca más en los acontecimientos cercanos al 9 de febrero de 1913. Para ello, se basa en testimonios publicados tiempo después de los eventos, aunque algunos de ellos, pocos, tienen la frescura de lo inmediato: se trata de cartas o memorias escritas al poco de ocurridos los hechos sangrientos de la Decena Trágica, que los narradores vieron o en los que participaron.

Sin embargo, otros escritos más, y que nutren numerosas páginas de Cada quien morirá por su lado, fueron redactados mucho tiempo después de los sucesos de febrero de 1913 y se basaron en otras fuentes que, incluso (lo informa el propio Gilly), olvida citar. En particular, la obra de Martín Luis Guzmán, publicada a los 50 años de ocurridos los eventos, es fuente de constante uso para Gilly en varios de sus capítulos, si bien Martín Luis Guzmán al parecer no estuvo presente en los acontecimientos que narra y se basó, como insisto, en los informes de otros autores y no en su propio testimonio. ${ }^{7}$ Sin que lo diga de manera explícita, Gilly se propone complementar el texto de Martín Luis Guzmán con una añadidura: donde este último simplemente narra los hechos, Gilly los recoge y los usa para acusar de traidores a Huerta o, como lo discutiré abajo, al propio Pedro Lascuráin.

Lo interesante del caso $-\mathrm{o}$ lamentable, según se vea- es que Adolfo Gilly, quien reproduce con detenimiento los eventos del domingo 9 de

${ }^{7}$ Es fundamental recordar el peso que un testimonio tiene en su relación entre el lapso transcurrido del instante en que ocurrieron los hechos al momento en que el "testigo" (o al menos el contemporáneo a esos hechos), los consignó en el papel. En términos generales, entre más tiempo pasa entre los hechos y el relato escrito de esos hechos, menos confiable es su contenido. Fred Morrow Fling dice: "Entre más largo el intervalo de tiempo, menos fidedigno es el registro escrito; se trata de un problema de memoria. Entre más remoto el evento descrito por un testigo, menos puede recordar acerca de éste y más inseguro se encuentra en cuanto a la verdad de lo que puede recordar". Esto se relaciona directamente con el texto de Martín Luis Guzmán, puesto que uno se pregunta -al menos yo lo hicequé tanto de lo que reporta en realidad ocurrió o se debe a diferentes versiones que leyó o escuchó, sin contar los 50 años transcurridos cuando describió los acontecimientos de la Decena Trágica. Véase Fred Morrow Fling, The Writing of History, 1920, New Haven, Yale University Press, p. 69. 
febrero, tiene una hipótesis definida de antemano y, en cada caso en el que asoma más de una lectura de los hechos, se decide por una postura tomada a priori, a saber: en las contadas ocasiones en que Victoriano Huerta expresó su parecer respecto a participar (o no) en un levantamiento en contra Madero, el general siempre se mostró distante y a lo sumo recalcó la necesidad de encontrar el momento preciso para cualquier tipo de asonada. ¿Significa esto que Huerta mentía, como asume Gilly, o que el general simplemente expresaba lo que cualquier otro militar diría cuando se le invitara abierta o encubiertamente a participar en una rebelión en contra de las fuerzas establecidas?

Gilly, gracias a un empecinamiento inexplicable por no apartarse un ápice de la historia oficial, decide que todas son pruebas irrefutables de que Huerta, el conspirador por antonomasia, mentía: era él y nadie más quien preparaba desde tiempo atrás su gran traición. Pero, ¿por qué no permitir que surja otra hipótesis? Esto es, ¿en efecto a Huerta no le interesaba involucrarse en complot alguno y cuando participó fue por razones absolutamente prácticas y en respuesta a las circunstancias del momento? Pese a que los documentos que cita Gilly permiten desarrollar esta segunda hipótesis, el autor la puso a un lado porque no coincidía con lo que ya esperaba encontrar en esos mismos documentos. Huerta, lo repito, era un hombre extraordinariamente práctico; lo fue hasta el final de su vida, si bien en ocasiones se dejó llevar por "consejeros" cercanos y cometió errores de todo tipo (el peor de todos: planear, en 1915, su regreso de España a México, vía Estados Unidos). ${ }^{8}$

Como hombre práctico $-\mathrm{y}$ los documentos que usa Gilly permiten ampliamente establecer esta hipótesis-, Huerta era un oportunista. No

${ }^{8}$ Según George J. Raush, a Huerta lo convenció un oficial del almirantazgo alemán para que regresara a México: "En febrero de 1915 [...] el capitán Franz von Rintelin, visitó a Huerta en Barcelona y ofreció apoyar un golpe militar a favor del general que lo restauraría en el poder en México. [...] Aunque parece que Huerta no llegó a un acuerdo definitivo con Rintelin, él se sintió indudablemente intrigado con las posibilidades tendidas por el [militar] alemán. Ahora Huerta tenía tanta esperanza de retornar exitosamente a México como para convencerlo de que debía esforzarse. El 31 de marzo [de 1915] Huerta zarpó de Cádiz en el vapor Antonio López de la compañía naviera española con destino [a] Nueva York", George J. Raush, "Victoriano Huerta: A Political Biography", 1960, University of Illinois, tesis de doctorado, p. 235. Mark Wasserman, por su parte, en su artículo sobre Enrique C. Creel, escribe: "Creel viajó a España en 1915 para persuadir al depuesto Huerta de que participara en una revuelta planeada y patrocinada por la inteligencia alemana. El complot se derrumbó cuando Huerta y [Pascual] Orozco, sus colíderes, fueron capturados [...] en Estados Unidos", Mark Wasserman, "Enrique C. Creel: Business and Politics in Mexico, 1880-1930", The Business History Review 1985, 59.4, pp. 645-62, en especial p. 659. Aunque Raush no menciona a Creel, ni Wasserman a Rintelin, ambos coinciden con que había una presencia alemana clave como parte del complot. 
se preocupó en momento alguno por conspirar, es cierto; pero cuando vio que una conspiración podía funcionar, se vinculó a ella. Mi punto en discordia con el profesor Gilly y con todos quienes coinciden con su postura (o con quienes Gilly coincide) es cuándo decidió Huerta unirse a la conjura y con ello traicionar, como repiten los oficialistas, a Madero. ¿Sucedió esto el 9 de febrero de 1913, cuando bajó del coche de alquiler en el momento justo en que el presidente se acercaba a Palacio, para simbólicamente reafirmar su poderío? O, como yo propongo, ¿se decidió por unirse a los sublevados días más tarde, cuando vio la imposibilidad de tomar la Ciudadela?

Para Gilly esta última puede ser una pregunta inocua, y quizá lo sea, pero dista de ser retórica. Importa saber cuándo decidió Huerta unirse a uno de los muchos complots que ya se urdían en contra de Madero y del maderismo. Si el 9 de febrero y antes de bajarse del automóvil para ofrecer sus servicios incondicionales a Madero el general ya había decidido tomar el gobierno, entonces concuerdo con Gilly en cuanto a que Huerta era un traidor; si, por el contrario, éste esperó hasta el último momento para unirse a la conjura, cuando se convenció de lo inútil que era continuar una guerra en el centro de la ciudad, entonces fue más un oportunista que un traidor. Ciertamente, y dependiendo de cómo se conteste a mi pregunta, el asesinato de Madero - cuya orden se ha achacado insistentemente a Huerta y que Gilly asume como cierta, a partir de las palabras de Manuel Márquez Sterling, a quien él llama erróneamente "embajador" cubano- ${ }^{9}$ pudo haber sido o no maquinado por el propio Huerta. En este punto, el lector habrá adivinado que me pronuncio en contra de toda teoría de la conspiración; que creo que a Huerta se le ha acusado injusta, aunque no gratuitamente, de traicionar a Madero, y que me opongo a adjudicar a Huerta la muerte del presidente a partir de pruebas circunstanciales. Hasta ahora, nadie ha probado de manera irrefutable que Huerta ordenara el asesinato de Madero y el profesor Gilly no ha aportado en

${ }^{9}$ Cfr. op. cit., p. 65. Aunque el profesor Adolfo Gilly escribe con acierto y determinación en la p. 92 de su obra que "embajador hay uno solo" -y con esto se refiere al representante diplomático de Estados Unidos- en varias páginas de su libro olvida sus palabras y llama embajadores a otros miembros del cuerpo diplomático que eran solo ministros plenipotenciarios. Embajada había una $\mathrm{y}$, salvo los casos de consulados generales como el suizo, el resto lo conformaban legaciones. En la pp. 132-133, Gilly repite: "esa mañana del sábado 15 , cuatro embajadores [sic] primero por conducto de [Bernardo de] Cólogan, y una representación de veinticinco senadores, habían ido a Palacio Nacional a pedir la renuncia lisa y llana del presidente". Estos yerros, de consecuencia para la historia diplomática de nuestro país, revelan cuán poco cuidadoso fue el autor en el desarrollo de su obra. 
esta obra documento alguno que corrobore esa hipótesis carrancista. ${ }^{10}$

La secuencia de los hechos importa poco a Gilly (p. 79) cuando dicha secuencia -trátese de cuándo Madero nombró a Huerta comandante militar de la plaza o de cualquier otro hecho-es crucial. A Huerta le interesaba y convenía el puesto de comandante y no lo iba a abandonar por una aventura militar, si no fuera por razones fundamentales. Dejar el puesto recién adquirido por unirse a una banda de rebeldes no era parte de su estilo; a menos, claro, que viera la situación perdida, como quizá la vislumbraba cuando se percató de las dificultades reales que implicaba la toma de la Ciudadela, en donde se encontraban atrincherados Díaz y Mondragón. Lo que es seguro es que Gilly se apresura en sus conclusiones: basándose en el testimonio de un individuo que vio en retirada las tropas de Mondragón y Díaz, Gilly

${ }^{10}$ Es irónico que Gilly perpetúe en esta obra las tesis de los seguidores de Carranza, el mismo que se negó a impedir que un pelotón fusilara a su héroe, el general Felipe Ángeles. En marzo de 1915, Ángeles escribió de la lucha armada que ellos, los convencionistas, sostenían "desde que el señor Carranza y sus partidarios se declararon, públicamente, 'preconstitucionalistas' o amigos de un nuevo género de dictadura con don Venustiano, hombre incapaz de gobernar de cualquier modo, a la cabeza". Carranza, incapaz de gobernar, tal vez; capaz de ordenar fusilamientos y asesinatos, seguramente. Para las palabras de Ángeles véase NYPL ELLP. Carta del general Felipe Ángeles al licenciado Enrique C. Llorente. Monterrey, Nuevo León, 5 de marzo de 1915. concluye que ambos generales $i$ "estaban derrotados”! ¿En dónde está escrito, me pregunto, que un ejército que retrocede está necesariamente vencido?

En el párrafo que cito, Gilly alude de manera indirecta a una forma peculiar de escribir historia: la basada en hechos puros y discernibles. Puede funcionar y ser creíble esta forma de historiar, lo fue durante siglos; pero en otras partes de su obra, Gilly transgrede esta norma y llega a veces a conclusiones basadas en su sentir y no en los documentos que cita para espantar al neófito lector. De ahí que su postura confunda, cuando acusa (como quienes defienden la versión oficialista del pasado mexicano) a Huerta de conspirar y de haberlo planeado todo desde el inicio: visión simplista, que carece de todo el fundamento que Gilly le pretende otorgar.

Un capítulo en particular, el más original de todos, pero que no embona por sus detalles con el resto de la obra, refuta la teoría de la conspiración de Gilly. Basado en las memorias de la señora inglesa Rosa E. King y en materiales provenientes de los archivos de la Secretaría de la Defensa Nacional, el capítulo pormenoriza el viaje relámpago de Madero a Cuernavaca, para encontrarse con el "único" militar fiel a su causa: el protagonista de décadas de Gilly, 
el general Felipe Ángeles. Según los datos que Gilly presenta, Madero permaneció en el hotel de la señora King la noche de su arribo a Cuernavaca e hizo otro tanto en Churubusco a su retorno (p. 89). De ser esto cierto, y a pesar de que Madero dejó dicho antes de partir que iría a Toluca y no a Cuernavaca, es demasiado cándido pensar que Huerta no estuviera enterado del paradero de su presidente; pero lo es más asumir que, si como lo afirma Gilly, Huerta estaba conspirando, no se aprovechara de la ausencia de más de 48 horas de Madero para asumir la presidencia con un verdadero segundo golpe de Estado. Si ya complotaba Huerta, ¿cómo se explica que, ausente Madero, no asumiera el poder? La teoría de la conjura que asume Gilly recuerda a un diálogo famoso entre Groucho y Chico Marx:

"El cuadro que buscan se encuentra escondido en la casa de al lado", asegura Groucho.

Su hermano Chico descorre la cortina, mira por la ventana y replica alarmado: " No hay casa de al lado!" "Entonces edificaremos una", concluye Groucho. ${ }^{11}$

${ }^{11}$ Para otra reconstrucción del diálogo entre los hermanos Marx, véase, por ejemplo, http://downwithtyranny.blogspot.mx/2010/12/thurber-tonight-letyour-mind-alone.html (fecha de acceso: 17 de junio de 2013).
Una y otra vez los historiadores oficialistas han acudido a la teoría de la conspiración para explicar el ascenso vertiginoso de Huerta a la presidencia, seguida (o acompañada) del asesinato de Madero y José María Pino Suárez. Pregunto: ¿en qué basan estos autores dicha teoría, más allá de presentar pruebas circunstanciales? Huerta se descuidó y, contrario a lo que había ofrecido, no protegió de los otros generales y civiles complotistas las vidas de Madero y Pino Suárez; esto es irrefutable. Pero una cosa es que un general, entre otros (con su poder e influencia coartados por quienes lo rodeaban), tratara de mantenerse en el poder por encima de estos últimos, y otra que, en febrero de 1913, Huerta tuviera el poder absoluto que asumió meses más tarde (sobre todo, como asegura Gilly, para ordenar el asesinato de dos personas que, alejadas del poder, habían dejado de interesar a Huerta. ${ }^{12}$ Presidente durante los primeros días después del cuartelazo, no era el Huerta presidente de octubre

12 "La evidencia de que Huerta ordenara matar a Madero y Pino Suárez”, escribieron los historiadores estadounidenses William L. Sherman y Richard E. Greenleaf, "no es nada más que circunstancial". Para apoyar sus palabras, ambos autores recogieron, a su vez, las opiniones de otros historiadores mexicanos. Véase William L. Sherman y Richard E. Greenleaf, Victoriano Huerta: A Reappraisal, 1960, México, Mexico City College, p. 84. 
de 1913. ${ }^{13}$ Esta "sutil" diferencia la obvia Gilly, para quien la clave de la conjura se encuentra literalmente en una ubicación inexistente, por inventada: la casa de al lado.

Para apoyar su tesis, Gilly privilegia memorias y otros documentos publicados al menos meses después de que Venustiano Carranza -otro personaje que no olvidaba humillaciones ni "traiciones"- asumiera el poder absoluto, gracias al apoyo político y castrense de Woodrow Wilson desde su llegada a la Casa Blanca. Todo lo que muchos de los autores publicaron después de que Carranza ocupara la presidencia, lo hicieron

${ }^{13}$ En el primero de sus libros sobre el gobierno del general Victoriano Huerta, Edith O'Shaughnessy, esposa del agregado de asuntos de la embajada estadounidense y confidente del general mexicano, escribió: "Él [Huerta] insiste siempre en que no asesinó a Madero", Edith O'Shaughnessy, A Diplomat's Wife in Mexico, 1916, Nueva York, Harper \& Brothers, p. 215. En varias entrevistas que concedió a la prensa norteamericana, Huerta aseguró su inocencia tocante al asesinato de Madero; ante el Boston Daily Globe, el ex presidente provisional, tras afirmar "con vehemencia" que no había tenido "nada que ver con la muerte de Francisco Madero", declaró que "él sabía quién fue responsable de la muerte de Madero, pero que se lo guardaba en calidad de 'secreto profesional'", Boston Daily Globe, 16 de abril de 1915. Justo un año más tarde, Huerta aseguró frente a un reportero del New York Times, que conocía al asesino de Madero. Aseveró, además, que "pronto" se conocería la verdad de lo acontecido (New York Times, 16 de abril de 1916). Aunque ese "pronto" nunca llegó, no hay razón alguna (más allá de las que esgrime la postura oficialista de la historia) para desconfiar, a priori, de las palabras de Huerta. para distanciarse de Huerta y, de ser posible asumir un papel protagónico, en particular en lo que tocaba a sus intentos, todos ellos fallidos, por alertar a Madero del "traidor" Huerta y así salvar la vida del presidente. Gilly se preocupa poco por cuestionar estos "testimonios" y toma al pie de la letra sus aseveraciones: ¿debo añadir que lo hace porque dichas aserciones concuerdan con su visión y versión de la conjura encabezada por Huerta en contra de Madero?

Uno de los testimonios en que el autor se apoya es el del ministro plenipotenciario español de origen canario, Bernardo de Cólogan y Cólogan. La declaración, cuyo original se encuentra en el Archivo Histórico Genaro Estrada de la ciudad de México, la mecanografió cuando Huerta había abandonado el país y dista mucho de su postura inicial frente al general, a quien apoyó ante su gobierno en varias ocasiones. Gilly cita la transcripción publicada de este documento e ignora la historia detrás de él. Por considerar a Madero incapaz de gobernar, Cólogan apoyó la presidencia de Huerta desde el inicio; en lo que tocaba a elegir entre Huerta y Félix Díaz, el representante español no tenía ningún inconveniente en que Huerta permaneciera en el poder. Así relató Cólogan lo acontecido en un banquete 
en "el elegante Jockey Club" dedicado a los generales Díaz y Mondragón, que presidió el propio Huerta a fines de abril de 1913:

Asistimos los representantes extranjeros, aunque hubo algún refunfuño. El General Félix Díaz, hombre de muy pocas palabras, contestó brevemente el brindis que un miembro del Club le dirigió, por la concordia de los mexicanos, por la paz y la justicia, que fue su lema. Luego habló profusamente el General Huerta con su humorismo campechano, en que nos dijo no entendía de cosas de Gobierno, ni de sociedad, sino de soldados, y que Dios lo hizo feo pero sin miedo y completo. Hizo declaraciones sustanciosas que impresionaron: que por encima de las leyes está la necesidad de vivir [...]; [que] dentro de dos meses habría pacificado al país, y se verificarían las elecciones; [que] no tenía sino una cabeza y dos brazos, y necesitaba la cooperación incondicional de quienes, como los miembros del elegante Club, tenían intereses y propiedades por qué velar, y haría la paz al precio de su vida, y cueste lo que cueste. ${ }^{14}$

¿A qué se debe la gran diferencia de tonos entre ésta y la carta que rescata Gilly? Al menos durante la primera mitad de 1913, Huerta para

${ }^{14}$ MAEC AG. Signatura H 16159. Bernardo J. de Cólogan al ministro de Estado. México, 28 de abril de 1913.
Cólogan era un hombre capaz y divertido. Por su parte, Huerta hacía hasta lo imposible por complacerlo; cierto que Cólogan fue cambiando su postura ante el general conforme avanzó el tiempo y el gobierno de Huerta enfrentó situaciones más difíciles y complicadas. Cólogan se impacientaba. Para septiembre ya hablaba del general como "indio avisado". ${ }^{15}$ Huerta iba perdiendo sus favores; pero la situación llegó a su punto de ebullición cuando, en una reunión, Cólogan, a espaldas de Huerta, escuchó decir al general que "ningún español era de fiar". A partir de ese instante, Cólogan guardó hacia Huerta un gran resentimiento, sin volverlo público.

De ahí a que Cólogan escribiera motu proprio la carta que cita Gilly, hay una gran distancia. Añado otro antecedente inmediato a esa carta y que explica mejor el tenor en el que está escrita: Cólogan, como ministro plenipotenciario español, ansiaba convertirse en embajador, y sabía que México era el lugar en donde podría alcanzar el puesto. Al distanciarse de Huerta y acusarlo de asesino y traidor-como después muchos otros también lo hicieron-, Cólogan buscaba que Carranza reconsidera-

\footnotetext{
${ }^{15}$ MAEC AG. Signatura H 16159. Despacho 152. Bernardo J. de Cólogan al ministro de Estado. México, 17 de septiembre de 1913.
} 
ra su decisión de echar del país a todo diplomático que hubiese tratado personalmente con el general. Esa carta "confidencial" que cita Gilly representó el esfuerzo postrero (y desesperado) del ministro español por permanecer en el país y convertirse a la larga en embajador de España en México. Carranza guardó su carta pero, como hizo con la mayoría de los ministros europeos, obligó a Cólogan a marcharse del país. La validez de ese documento es, por tanto, limitada, y muchas de sus afirmaciones deben tomarse con cuidado.

Otro apartado original en la obra se basa en informes rendidos por el ministro chileno, Anselmo Hevia, que permite reconstruir lo que aconteció con la renuncia a la presidencia $\mathrm{y}$ vicepresidencia que firmaron Madero y Pino Suárez. Originalmente, dicha dimisión firmada debía quedar protegida en manos de Hevia y entregada a Huerta en Veracruz, cuando ya estuvieran Madero y los suyos a bordo del buque que los transportaría a La Habana. Pedro Lascuráin, sin embargo, insistió en guardar la renuncia; pero, por razones desconocidas, entregó la dimisión firmada a Huerta para que éste acelerara los pasos para llegar -mediante Lascuráin- a la presidencia. Lo anterior, para Gilly, convierte a este último en traidor y demuestra, una vez más, que Huerta planeaba desde un inicio deshacerse de Madero y Pino Suárez. Como ocurrencia tardía, queda una gran pregunta: ¿"En qué momento y hora decidió Huerta la ejecución" de ambos? La respuesta de Gilly: "no lo sabemos".

$\mathrm{Al}$ término de mi lectura de Cada quien morirá por su lado - palabras tomadas de una publicación del general Felipe Ángeles (p. 182)- me percaté que este libro lo escribió Adolfo Gilly con los testimonios de los amigos (como el ministro chileno Hevia) o seguidores de Madero. Las fuentes de Gilly (pese a la buena bibliografía que aparece antes del índice de su obra) lo revelan: Felipe Ángeles, militar, protagonista de batallas legendarias y cuya figura aparece en esta obra con persistencia; el una vez villista Martín Luis Guzmán, quien reconstruyó con ayuda del testimonio de otros lo ocurrido en febrero de 1913; el ministro cubano Manuel Márquez Sterling, ex periodista y retratista que pinta de manera extraordinaria a los personajes que introduce en sus memorias; fue quien pasó una noche en la intendencia de Palacio junto con Madero, Ángeles y Pino Suárez... Gilly se apoya también en autores más recientes como el finado Friedrich Katz -a quien Gilly dedica su obra- y Antonio Saborit, quien compartió con el autor de Cada quien morirá por su lado 
muchos documentos (poemas incluso) e ideas clave. ${ }^{16}$

Gilly no leyó a autores críticos de Madero (aunque es cierto que no alaba tanto al ex presidente en estas páginas), mucho menos examinó la obra de autoras como Edith O’Shaughnessy, quien además de vivir bajo las presidencias de Madero y Huerta junto con su marido (encargado de la embajada estadounidense, después de que a Henry Lane Wilson lo removiera el presidente de su país), se volvió amiga cercana y admiradora del general Victoriano Huerta. Agrego que, en casos como el de la inglesa Rosa E. King -dueña de una ex hacienda convertida en hotel-, Gilly no citó los halagos de King a Huerta. El partidismo político del profesor Gilly, sus preferencias ideológicas, cerraron el paso a una obra que pudo aportar mucho a lo que ignoramos sobre la Decena Trágica.

Yo retorno a mi símil del comienzo: el afán por utilizar viejas piezas para reconstruir un reloj de péndulo fue un acto fallido. Poco encontrará de novedoso el lector de esta obra, más allá de descubrir que, al lado del de Huerta, se deben colgar en el muro de los acusados, también los cuadros de los traidores Pedro Lascuráin y el "elegante" Francisco León de la Barra y, ¿por qué no?, del propio ministro plenipotenciario de España en México, Bernardo J. de Cólogan y Cólogan. El libro de Gilly contiene innumerables aseveraciones que no respalda autor o documento alguno; afirmaciones que posteriormente desarrolla y toma como verdades irrefutables. Encontré también notas al calce que no correspondían al texto que supuestamente apoyaban. Escrita deprisa -salvo por la ya mencionada bibliografía que proporciona pistas novedosas-, ayudará poco al interesado en conocer más de los sangrientos acontecimientos de febrero de 1913 que, contra toda esperanza de sus coetáneos y para desazón de los historiadores oficialistas, permitieron a Victoriano Huerta tomar el poder.

\footnotetext{
${ }^{16}$ Uno de dichos poemas, de Alfonso Reyes, que aparece en la p. 82 de la obra de Gilly, contiene la frase que sirvió a Saborit de título para su compilación más reciente sobre la Decena Trágica: "Febrero de Caín y de metralla", véase Antonio Saborit, Febrero de Cain y de metralla: la Decena Trágica, una antología, 2013, México, Cal y Arena.
} 